Original article

\title{
Global DNA methylation of brain neurons in acute poisoning with clozapine and its combination with alcohol: An experimental study
}

\author{
Anastasiya S. Babkina, Maryam B. Khadzhieva, Irina V. Ostrova, Ivan A. Ryzhkov, Arkady M. Golubev \\ Federal Research and Clinical Center of Intensive Care Medicine and Rehabilitology, Moscow, Russia
}

Received 4 December 2020, Revised 6 April 2021, Accepted 7 July 2021

(C) 2020, Russian Open Medical Journal

\begin{abstract}
Background - Acute poisoning with atypical neuroleptic clozapine is characterized by rapid progression, high risk of death and severe neurological manifestations. Neurotoxic effects of this pharmaceutical drug have also been reported at therapeutic doses. The pathogenesis of brain damage in acute clozapine poisoning is not fully understood. Changes in DNA methylation level may play an important role in the mechanisms of drug neurotoxicity. The available data on the effect of clozapine on brain cell DNA provide a rationale for studying the epigenetic aspects of the pathogenesis of acute poisoning with this neuroleptic agent.

The objective of our study was to evaluate the global DNA methylation level in rat brain neurons in acute poisoning with clozapine and its combination with ethanol.

Material and methods - Clozapine $-150 \mathrm{mg} / \mathrm{kg}$ in $2.0 \mathrm{ml}$ of normal saline solution, or clozapine $-150 \mathrm{mg} / \mathrm{kg}$ in $2.0 \mathrm{ml}$ of $40 \%$ ethanol were administered via a gastric tube to adult male Wistar rats $(n=21)$ under anesthesia with sevoflurane. In the control group, saline was administered via a gastric tube. Animals were euthanized four hours after drug administration. Autopsy was performed with the collection of brain samples for histochemical examination and determination of the DNA methylation level using the fluorometric method. To detect DNA in sections of paraffin-embedded tissue, we used the Feulgen staining. The TUNEL method was employed to detect DNA fragmentation.

Results - An increase in the level of global DNA methylation in brain neurons was found in the clozapine and clozapine+ethanol groups. The average level of methylated DNA in the clozapine+ethanol group was higher than in the control group or clozapine group (2.56 \pm 0.31 vs. $1.35 \pm 0.1, p=0.007$ and $1.70 \pm 0.33, p=0.044$, respectively). An increase in the mean optical density of the cortical neuron nuclei was observed in the clozapine+ethanol group compared with the control group and clozapine group. DNA fragmentation was not detected in any experimental group.

Conclusion - Acute poisoning with clozapine in combination with alcohol caused an increase in the global DNA methylation level in brain neurons, which may have played a significant role in the pathogenesis of acute clozapine poisoning and could be an important factor in the neurotoxicity of this medication.
\end{abstract}

Keywords: acute drug poisoning, brain, neurons, DNA methylation, Feulgen reaction.

Cite as Babkina AS, Khadzhieva MB, Ostrova IV, Ryzhkov IA, Golubev AM. Global DNA methylation of brain neurons in acute poisoning with clozapine and its combination with alcohol: An experimental study. Russian Open Medical Journal 2021; 10: e0306.

Correspondence to Anastasiya S. Babkina. Address: 25/2 Petrovka St., Moscow 107031, Russia. Phone: +7 (965) 175 9578. Email: asbabkina@gmail.com.

\section{Introduction}

Clozapine is an atypical neuroleptic used for the therapy of treatment-resistant schizophrenia. Despite clozapine's high risk of side effects and toxicity, it is prescribed due to its high clinical efficacy [1, 2]. Bipolar and other psychiatric disorders are often associated with an increased risk of suicidal behavior, which may lead to poisoning with preparations used to treat these disorders.

Analysis of suicides among patients with psychiatric disorders suggested that clozapine poisoning is linked to higher risk of death than carbamazepine, lithium, risperidone, or chlorpromazine poisoning [3]. Pfeifer et al. have also showed that the highest mortality in psychotropic medication poisoning occurs with atypical neuroleptic clozapine and levomepromazine [4].

Strong and fast sedative effect of this drug has prompted its use with criminal intent. In most suicidal or criminal poisonings, clozapine is used in combination with other neuroleptic drugs or with alcohol [5].

The toxic effects of clozapine may occur even at a therapeutic dose and include myocarditis, cardiomyopathies, cardiac rhythm and conduction disorders, orthostatic hypotension, agranulocytosis, thrombosis, bowel obstruction, metabolic disorders, malignant neuroleptic syndrome, cerebral edema, and several other life-threatening conditions [6, 7].

Severe neurological manifestations, such as altered consciousness, dysarthria, ataxia, seizures, and even status epilepticus are typical for acute clozapine poisoning [8, 9].

Morphological brain studies of the victims who died within 24 hours after poisoning with clozapine combined with alcohol revealed an acute brain neuronal damage, both non-specific reversible and irreversible, as well as blood circulation disorders 
including microcirculatory congestion, and perivascular and pericellular edema [10]. Experiments in rats demonstrated brain neuronal damage four hours after administration of a sublethal clozapine dose [11].

Mechanisms of central nervous system damage in clozapine poisoning are not fully understood. Hence, according to the study by Elmorsy et al., clozapine neurotoxicity may be caused by disruption of the energy balance of microvascular endothelial cells. Clozapine was shown to inhibit the activity of mitochondrial complexes I and III [12]. Clozapine transformation into clozapine$\mathrm{N}$-oxide, which has a direct toxic effect on the brain, catalyzed by flavin-containing monooxygenase was discovered in the brain [13]. Some researchers indicate that clozapine can reduce the activity of the antioxidant enzymes, superoxide dismutase and catalase [14, 15]. Polydoro et al. showed increased levels of reactive oxygen species and thiobarbituric acid in striatum and hippocampus of rats receiving clozapine for 28 days [16]. Administration of therapeutic doses of clozapine for 1-3 weeks caused DNA damage in neurons and cardiomyocytes $[15,17]$. There is limited evidence for the effect of toxic doses of clozapine on epigenetic DNA modifications [18, 19].

DNA methylation is one of the mechanisms of gene regulation. The 5-mC methyl group inhibits binding of transcription factors to their CpG-containing recognition site, which leads to gene downregulation [20]. Gene dysregulation due to DNA hypermethylation could be an important factor in the pathological condition development [21]. Changes in DNA methylation levels were shown to play a significant role in neurotoxic mechanisms of some medications $[20,22]$. Since DNA methylation is a flexible process, responding rather quickly to exposure to various exogenous factors [23], the study of epigenetic aspects of acute poisoning pathogenesis appears quite relevant.

The objective of our study was to evaluate the global DNA methylation level in rat brain neurons in acute poisoning with clozapine or its combination with alcohol.

\section{Material and Methods}

The experiments were performed in accordance with the Directive 2010/63/EU of the European Parliament and of the Council of the European Union on protection of animals used for scientific purposes. All applicable international and national guidelines for working with laboratory animals were followed during this study. The study protocol was approved by the local research ethics committee at the Federal Research and Clinical Center of Intensive Care Medicine and Rehabilitology. The study was conducted on adult male Wistar rats weighing 200-250 g $(n=21)$. Group I (control, $n=8$ ) received $2.0 \mathrm{ml}$ of $0.9 \% \mathrm{NaCl}$ solution under general anesthesia with sevoflurane enterally through the tube, Group II (clozapine group, $\mathrm{n}=8$ ) was administered with clozapine $150 \mathrm{mg} / \mathrm{kg}$ in $2.0 \mathrm{ml}$ of $0.9 \% \mathrm{NaCl}$ solution, Group III (clozapine+ethanol group, $\mathrm{n}=5$ ) was given clozapine $150 \mathrm{mg} / \mathrm{kg}$ in $2.0 \mathrm{ml}$ of $40 \%$ ethanol. Four hours after administration of indicated solutions, euthanasia was performed via cervical dislocation under general anesthesia with sevoflurane. Then an autopsy was performed with brain samples taken for histochemical studies and DNA methylation level determination.

\section{Determining global DNA methylation levels}

Brain samples of experimental animals $(n=21)$ were stored in RNA stabilization solution (Eurogen, Russia) at $-20^{\circ} \mathrm{C}$ for further DNA isolation using AllPrep DNA/RNA/miRNA Universal Kit (50) (QIAGEN, Germany) laboratory reagents in accordance with the manufacturer's instructions. Purity of DNA extraction was tested by a spectrophotometer ( $\mu$ Drop Plate for Multiskan GO, Thermo Fisher Scientific, USA). The $260 \mathrm{~nm} / 280 \mathrm{~nm}$ ratio ranged from 1.6 to 2.1 , while $260 \mathrm{~nm} / 230 \mathrm{~nm}$ ratio varied from 1.7 to 2.1 . Quantification of isolated DNA was performed using a Qubit 2.0 fluorimeter (Life Technologies, Germany). Assessment of the global DNA methylation level (5-mC \%) was performed by the fluorimetric method on a CLARIOstar microplate reader using the Methylated DNA Quantification Kit (Fluorometric, Abcam, UK) at excitation wavelength of $530 \mathrm{~nm}$ and fluorescence wavelength of $590 \mathrm{~nm}$. The recommended DNA quantity per reaction, according to the instructions, was $100 \mathrm{ng}$ (permissible range 20-200 ng); for each sample, the reaction was performed in two replicates.

\section{Histochemical study}

As a fixative for the histochemical study of brain samples, we used $10 \%$ neutral buffered formalin. After that, the material was dehydrated in increasing concentrations of ethanol and embedded in paraffin according to the conventional technique. A rotary microtome (Sakura, Japan) was used to make 5-6 $\mu \mathrm{m}$ thick frontal brain sections.

To detect DNA in paraffin sections, we used Feulgen staining (BioVitrum, Russia). Cold hydrolysis time was $60 \mathrm{~min}$ according to the instructions provided with the kit. The Nikon ECLIPSE Ni-U light microscope (Nikon, Japan) and a digital camera were used to obtain images of cortical sections at the $40 \times$ magnification. The histochemical reaction intensity was visually evaluated. Mean optical density (MeanDensity) and total optical density (SumDensity) of pyramidal neuron nuclei in the cortical layer II were quantified using NIS-Elements BR software (Nikon, Japan). MeanDensity was calculated as a mean of pixel density values. SumDensity was calculated as a sum of optical density (OD) values of pixels in evaluated area. SumDensity characterizes the quantity of substance in biological sections. It is calculated using the following formula:

$$
\mathrm{OD}=-\log \frac{\text { PixelIntensityValue } * 0,5}{\text { MaxIntensityValue }}
$$

We studied 150-200 neurons in 2 or 3 fields of view per each preparation. The mean $O D$ value was calculated for each preparation.

\section{TUNEL study}

DNA damage was identified by TUNEL (terminal deoxynucleotidyl transferase dUTP nick end labeling) using NeuroTACS II In Situ Apoptosis Detection Kit (\#4823-30-K, Trevigen, Inc., USA) following the manufacturer's instructions. Nuclease-treated sections (1:100) were used as a positive control.

\section{Statistical analysis}

Statistical analysis was performed by Statistica 7.0 software using one-way ANOVA followed by Fisher's LSD post-hoc test for multiple comparisons. Data are presented as mean \pm SD. The critical level of significance for statistical hypothesis testing was 0.05 . 


\section{Results}

Global DNA methylation levels in rat brain in acute poisoning with clozapine or its combination with alcohol

The results of the DNA methylation level measurement in brain of experimental animals are shown in Figure 1. Mean methylated DNA level in the clozapine+ethanol group was higher than in the control group and clozapine group ( $2.56 \pm 0.31$ vs. $1.350 \pm 0.1, p=0.021$ and $1.700 \pm 0.33, p=0.002$, respectively).

\section{Histochemical study of neurons}

Microscopic examination of Feulgen-stained rat brain sections showed different reaction intensities in experimental groups (Figure 2). The most intensive staining of neuronal nuclei was observed in the clozapine+ethanol group.

Image quantification revealed an increase in the mean optical density of cortical neuronal nuclei in the clozapine+ethanol group vs. the control group and clozapine group (Figure 3).

Reduced total optical density of Feulgen-stained neuronal nuclei was found in the clozapine+ethanol group vs. the control (Figure 4).

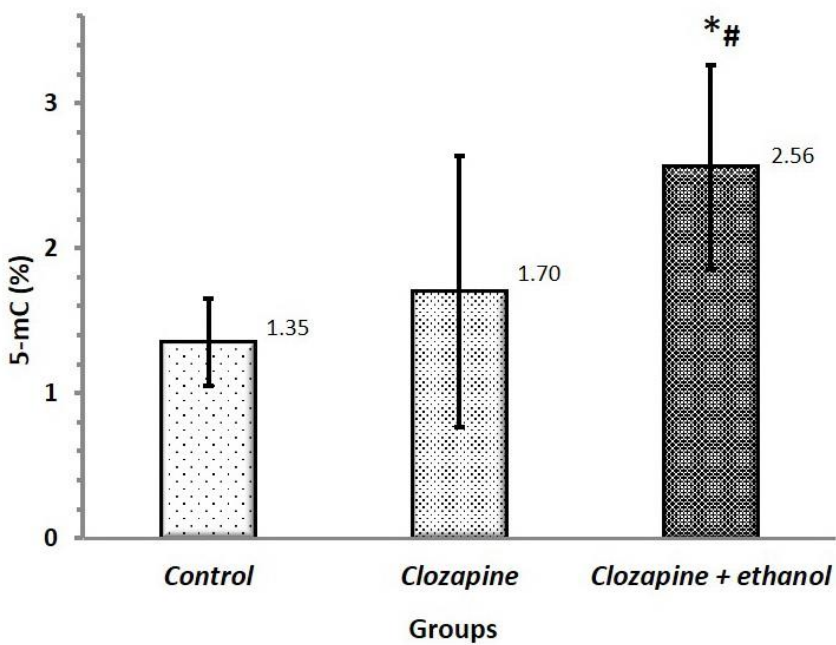

Figure 1. Genomic DNA methylation in rat brain in acute poisoning with clozapine and its combination with ethanol. The results are given as 5-mC $\%$ in relation to total genomic DNA in the sample, mean \pm SD. $* p=0.007$ vs. control, \# p=0.044 vs. the clozapine group.
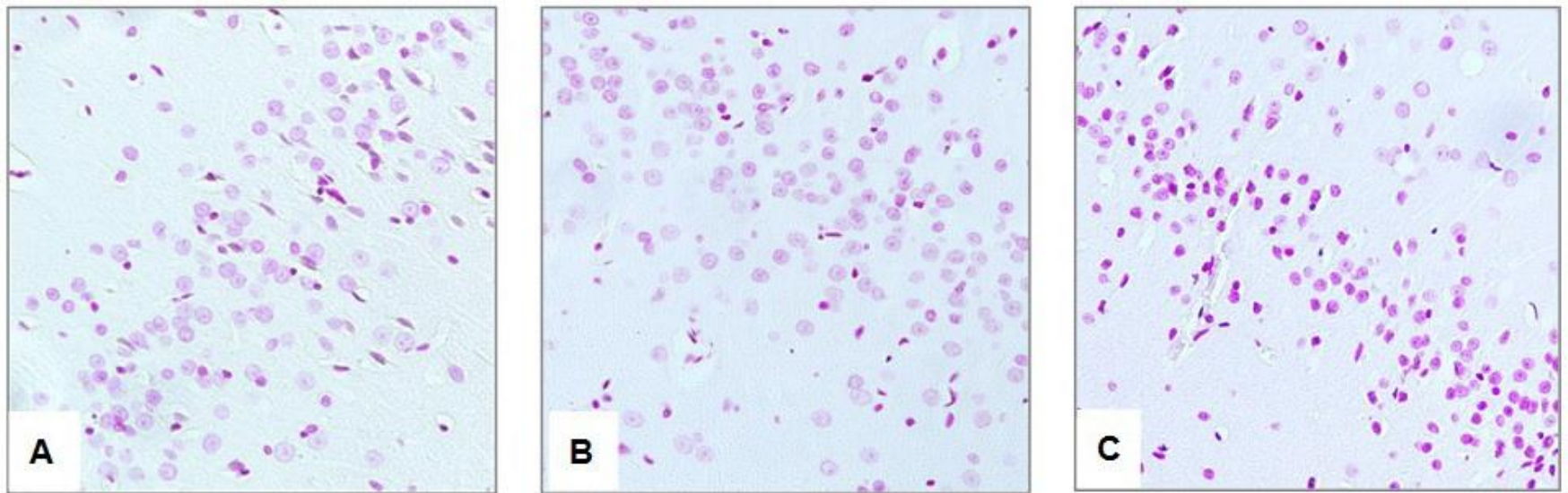

Figure 2. Rat cerebral cortex. Feulgen staining. Magnification 40x. (A) Control; (B) Four hours after administration of a sublethal dose of clozapine; (C) Four hours after administration of a sublethal dose of clozapine dissolved in $\mathbf{4 0 \%}$ ethanol.
TUNEL staining study

We used TUNEL technique to detect DNA fragmentation, resulting from apoptotic signaling cascade. In our study, no experimental group was found to have TUNEL-positive neuronal nuclei in the studied brain region (Figure 5).

\section{Discussion}

Our study has established enlarged global DNA methylation level of rat brain in acute poisoning with clozapine combined with ethanol.

The epigenetic theory of schizophrenia etiology and bipolar disorder has inspired several studies of the effects of neuroleptics on DNA methylation and demethylation in brain neurons. In contrast to haloperidol and olanzapine, clozapine is known to stimulate demethylation of hypermethylated promoter sites of GAD67 and RELN genes and to increase promoter-associated acetylation of H3K9 and H3K14 histones [24]. The study by Huang et al (2007) demonstrated that therapeutic doses of clozapine upregulated the histone methyltransferase MLL1 in the cerebral cortex, which caused the lysine 4 trimethylation of $\mathrm{H} 3$ histone (H3K4me3), resulting in transcription activation of the glutamate decarboxylase 1 (GAD1) gene [25]. Clozapine can also reduce methylation at the GADD45- $\beta$ gene locus in charge of regulating the cell cycle inhibition and participation in DNA repair [26].

Our data are supported by the evidence of increased global hypermethylation caused by toxic doses of clozapine. For example, in 2018, Swathy et al. showed that exposure of a human hepatocellular carcinoma cell line (HepG2) to clozapine at the maximum tolerated dose $(25 \mu \mathrm{M})$ led to 1.56 -fold increase in global DNA hypermethylation $(\mathrm{p}=0.004)$ due to elevated $5-\mathrm{mC}$ and $5-\mathrm{hmC}$ levels [18]. When studying the cytotoxic effect of clozapine on neutrophils in rats, condensation and subsequent destruction of chromatin structure were observed [19]. Global DNA hypermethylation is known to positively correlate with the formation of micronuclei. This could be caused by inactivation of DNA repair genes or hindered access to damaged DNA in chromatin [27]. 


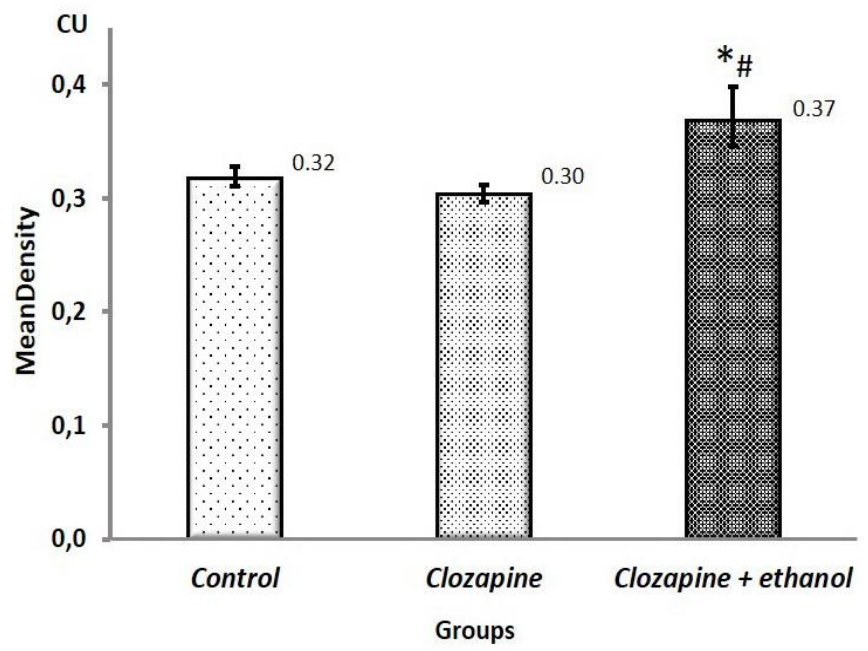

Figure 3. Mean optical density (MeanDensity) of Feulgen-stained neuronal nuclei in acute poisoning with clozapine and its combination with ethanol. Data are presented as mean $\pm S D$ ( $n=5$ per group). CU,

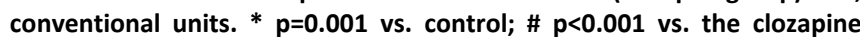
group.

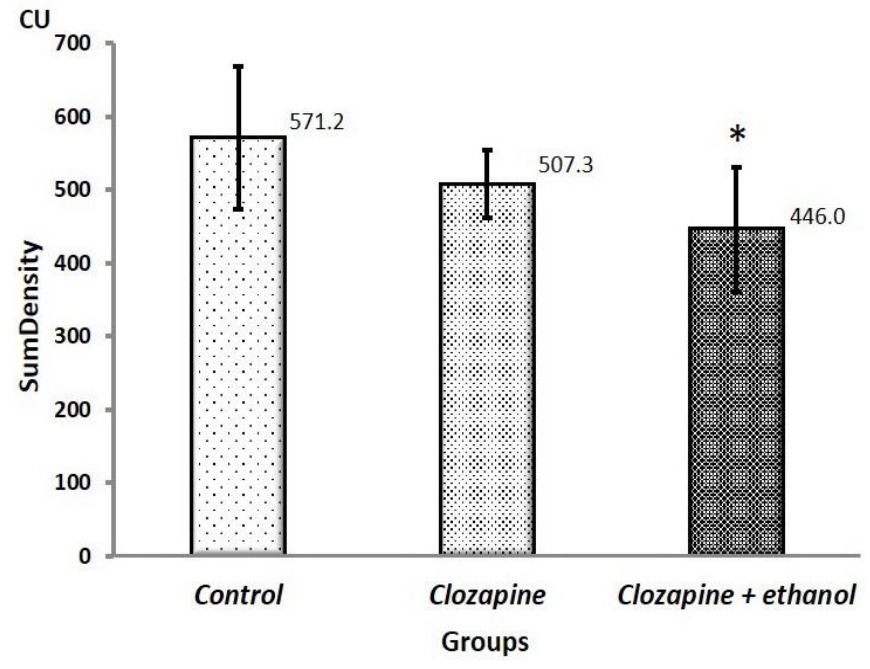

Figure 4. Total optical density (SumDensity) of Feulgen-stained neuronal nuclei in acute poisoning with clozapine and its combination with ethanol. Data are presented as mean $\pm S D$ ( $n=5$ per group). CU, conventional units. ${ }^{*} \mathrm{p}=0.028$ vs. control.
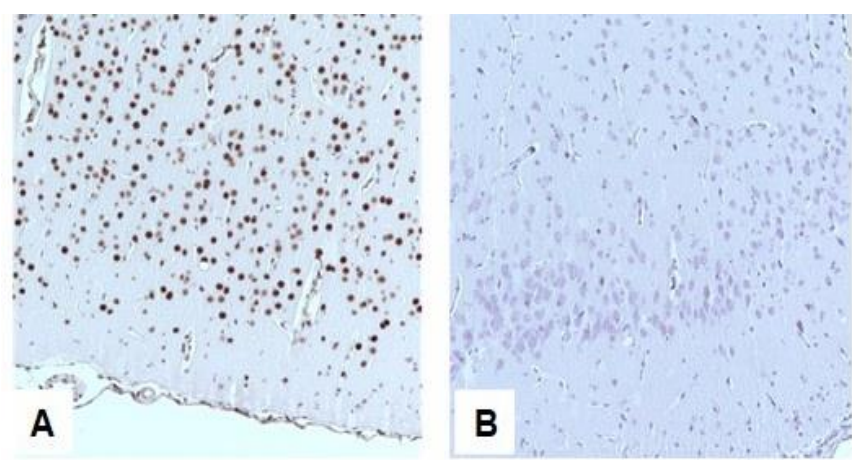

Epigenetic aspects of the ethanol effects could contribute significantly to the processes identified in our study. Increased global DNA methylation in peripheral blood cells in conditions of both chronic and acute ethanol intoxication has been reported by several studies $[28,29]$. However, examination of postmortem frontal cortex samples from patients with chronic alcohol intoxication revealed no significant differences in DNA methylation level versus the control group [30].

Elevated DNA methylation level in response to combined clozapine-and-ethanol exposure could be an initial stage of DNA alteration preceding its fragmentation. Augmented DNA methylation could be interpreted as a protective response to toxic exposure, since the change in chromatin structure may inhibit random (or nonspecific) gene transcription. The delayed effects of global DNA methylation in acute combined clozapine-ethanol poisoning are unknown, since global methylation level per se does not necessarily reflect the methylation status of active genes [31].

The Feulgen staining is the most precise histological technique for DNA identification, which allows studying DNA as a component of chromatin. Some researchers previously proposed that chromatin structure after the cell exposure to medications, carcinogens, and other exogenous factors can be evaluated using the Feulgen-stained histological sections [32]. The advantages of this technique over molecular biological methods include prolonged storage of materials, simplicity, and low cost of reagents.

Some studies demonstrated the relationship of epigenetic modifications of DNA with density and morphology of nuclei in Feulgen-stained preparations [32-34]. The results of our study demonstrated a significant reduction in the total optical density and increase of the mean optical density in the nuclei of brain neurons of the clozapine+ethanol group, compared with the control group and clozapine group. Changes in neuronal nuclei optical density and global DNA methylation level within the same experimental group may indicate the interrelation of the Feulgen reaction with epigenetic DNA modifications. Since total optical density characterizes DNA content per nuclear area, we suggest that chromatin condensed in the nucleus has a smaller distribution area, hence a lower total optical density. An increase of the mean optical density in the clozapine+ethanol group is probably due to the heterochromatin staining pattern. Some studies previously showed that reduction in the total optical density was associated with the loss of nuclear DNA fragments due to apoptosis [34]. However, the results of TUNEL staining, revealing no DNA fragmentation in any of our experimental groups, suggested that this mechanism was not the case in our study.
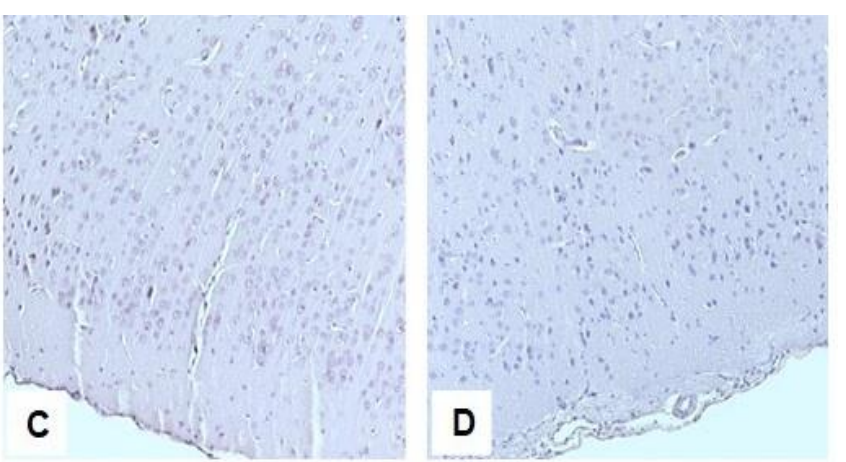

Figure 5. The cerebral cortex. TUNEL staining. Magnification 40x. (A) positive control, TUNEL-positive nuclei; (B) control group; (C) Four hours after administration of a sublethal dose of clozapine; (D) Four hours after administration of a sublethal dose of clozapine dissolved in $40 \%$ ethanol. 


\section{Conclusion}

Acute poisoning with clozapine combined with alcohol causes an increase in global DNA methylation of brain neurons. Consequently, DNA hypermethylation may play a significant role in the pathogenesis of acute clozapine poisoning being an important factor of neurotoxic clozapine effects.

\section{Conflict of interest}

The authors declare no conflicts of interest.

\section{Ethical approval}

All applicable international, national, and/or institutional guidelines for the care and use of laboratory animals were followed.

\section{References}

1. Green A, Tohen M, Patel JK, Banov M, DuRand C, Berman I, et al. Clozapine in the treatment of refractory psychotic mania. Am J Psychiatry 2000; 157(6): 982-986. https://doi.org/10.1176/appi.ajp.157.6.982.

2. Tochilov VA, Kushnir ON. Clozapine as a first-choice medication in the treatment of patients with acute psychoses. Social and Clin Psychiatry 2011; 21(2): 37-42. Russian. https://www.elibrary.ru/item.asp?id=17729265.

3. Ferrey AE, Geulayov G, Casey D, Wells C, Fuller A, Bankhead C, et al. Relative toxicity of mood stabilisers and antipsychotics: Case fatality and fatal toxicity associated with self-poisoning. BMC Psychiatry 2018; 18(1): 399. https://doi.org/10.1186/s12888-018-1993-3.

4. Pfeifer P, Greusing S, Kupferschmidt H, Bartsch C, Reisch T. A comprehensive analysis of attempted and fatal suicide cases involving frequently used psychotropic medications. Gen Hosp Psychiatry 2020; 63: 16-20. https://doi.org/10.1016/j.genhosppsych.2019.07.011.

5. Slyundin DG, Livanov AS, Anuchin VV, Merkin AG, Bobrinskaya IG, Gutova EV. Specific features of psychopathological manifestations in criminal clozapine intoxications. Neurology, Neuropsychiatry, Psychosomatics 2010; 2(3): 57-63. Russian. https://doi.org/10.14412/2074-2711-2010-102.

6. Flanagan RJ. Side effects of clozapine and some other psychoactive drugs. Curr Drug Saf 2008; 3(2): 115-122. https://doi.org/10.2174/157488608784529251.

7. Babkina AS, Golubev AM, Sundukov DV, Bashirova AR, Golubev MA. Clozapine: Mechanisms of toxicity and side effects. General Reanimatology 2018; 14(2): 35-45. Russian. https://doi.org/10.15360/1813-9779-2018-2-35-45.

8. Erdeljić Turk V, Kučan M, Vitezić D. Massive clozapine overdose: What to expect? Psychiatr Danub 2020; 32(3-4): 431-433. https://doi.org/10.24869/psyd.2020.431.

9. Lebin JA, Villarreal JD, Chen BC, Hall MK. Clozapine intoxication mimicking acute stroke. Clin Pract Cases Emerg Med 2018; 2(2): 155157. https://doi.org/10.5811/cpcem.2018.1.36734.

10. Bashirova AR, Sundukov DV, Babkina AS, Golubev MA, Telipov IN. Morphometry of cortical neurons in acute clozapine and ethanol poisoning. General Reanimatology 2020; 16(6): 19-30. https://doi.org/10.15360/1813-9779-2020-6-19-30.

11. Golubev AM, Sundukov DV, Churilov AA, Ershov AV, Romanova OL, Telipov INI. Purkinje cells of the cerebellum in clozapine and clozapine ethanol poisoning (experimental research). Russian Journal of Forensic Medicine 2019; 5(4): 9-14. https://doi.org/10.19048/2411-8729-20195-4-9-14

12. Elmorsy E, Smith PA. Bioenergetic disruption of human micro-vascular endothelial cells by antipsychotics. Biochem Biophys Res Commun 2015; 460(3): 857-862. https://doi.org/10.1016/j.bbrc.2015.03.122.
13. Fang J. Metabolism of clozapine by rat brain: The role of flavincontaining monooxygenase (FMO) and cytochrome P450 enzymes. Eur J Drug Metab Pharmacokinet 2000; 25(2): 109-114. https://doi.org/10.1007/BF03190076.

14. Reinke A, Martins MR, Lima MS, Moreira JC, Dal-Pizzol F, Quevedo J. Haloperidol and clozapine, but not olanzapine, induces oxidative stress in rat brain. Neurosci Lett 2004; 372(1-2): 157-160 https://doi.org/10.1016/j.neulet.2004.09.032.

15. da Costa Güllich AA, Coelho RP, Pilar BC, Ströher DJ, Galarça LA, Vieira $S M$, et al. Clozapine linked to nanocapsules minimizes tissue and oxidative damage to biomolecules lipids, proteins and DNA in brain of rats Wistar. Metab Brain Dis 2015; 30(3): 695-702. https://doi.org/10.1007/s11011-014-9621-5.

16. Polydoro M, Schröder N, Lima MN, Caldana F, Laranja DC, Bromberg E, et al. Haloperidol- and clozapine-induced oxidative stress in the rat brain. Pharmacol Biochem Behav 2004; 78(4): 751-756. https://doi.org/10.1016/j.pbb.2004.05.018.

17. Abdel-Wahab BA, Abdalla ME, El-khawanki MM. Does clozapine induce myocarditis, myocardial oxidative stress and DNA damage in rats? Egyptian Journal of Forensic Sciences 2014; 4(3): 75-82. https://doi.org/10.1016/j.ejfs.2014.04.001.

18. Swathy B, Saradalekshmi KR, Nair IV, Nair C, Banerjee M. Understanding the influence of antipsychotic drugs on global methylation events and its relevance in treatment response. Epigenomics 2018; 10(3): 233-247. https://doi.org/10.2217/epi-2017$\underline{0086}$.

19. Wasti A, Ghani R, Manji MA, Ahmed N. Clozapine induced neutrophi cytotoxicity in rats. J Pak Med Assoc 2006; 56(2): 62--65. https://pubmed.ncbi.nlm.nih.gov/16555636.

20. Forster VJ, McDonnell A, Theobald R, McKay JA. Effect of methotrexate/vitamin B12 on DNA methylation as a potential factor in leukemia treatment-related neurotoxicity. Epigenomics 2017; 9(9): 1205-1218. https://doi.org/10.2217/epi-2016-0165.

21. Landgrave-Gómez J, Mercado-Gómez O, Guevara-Guzmán R. Epigenetic mechanisms in neurological and neurodegenerative diseases. Front Cell Neurosci 2015; 9: 58 https://doi.org/10.3389/fncel.2015.00058.

22. Rudenko A, Tsai LH. Epigenetic modifications in the nervous system and their impact upon cognitive impairments. Neuropharmacology 2014; 80: 70-82. https://doi.org/10.1016/j.neuropharm.2014.01.043.

23. Mathers JC, Strathdee G, Relton CL. Induction of epigenetic alteration by dietary and other environmental factors. Adv Genet 2010; 71: 3-39. https://doi.org/10.1016/B978-0-12-380864-6.00001-8.

24. Dong E, Nelson M, Grayson D, Costa E, Guidotti A. Clozapine and sulpiride but not haloperidol or olanzapine activate brain DNA demethylation. Proc Natl Acad Sci U S A 2008; 105(36): 13614-13619. https://doi.org/10.1073/pnas.0805493105.

25. Huang HS, Matevossian A, Whittle C, Kim SY, Schumacher A, Baker SP, et al. Prefrontal dysfunction in schizophrenia involves mixed-lineage leukemia 1-regulated histone methylation at GABAergic gene promoters. J Neurosci 2007; 27(42): 11254-11262. https://doi.org/10.1523/JNEUROSCl.3272-07.2007.

26. Matrisciano F, Dong E, Gavin DP, Nicoletti F, Guidotti A. Activation of group II metabotropic glutamate receptors promotes DNA demethylation in the mouse brain. Mol Pharmacol 2011; 80(1): 174182. https://doi.org/10.1124/mol.110.070896.

27. Benedetti D, Lopes Alderete B, de Souza CT, Ferraz Dias J, Niekraszewicz L, Cappetta M, Martínez-López W, et al. DNA damage and epigenetic alteration in soybean farmers exposed to complex mixture of pesticides. Mutagenesis 2018; 33(1): 87-95. https://doi.org/10.1093/mutage/gex035.

28. Bönsch D, Lenz B, Reulbach U, Kornhuber J, Bleich S. Homocysteine associated genomic DNA hypermethylation in patients with chronic alcoholism. J Neural Transm (Vienna) 2004; 111(12): 1611-1616. https://doi.org/10.1007/s00702-004-0232-x. 
29. Zhang H, Gelernter J. Review: DNA methylation and alcohol use disorders: Progress and challenges. Am J Addict 2017; 26(5): 502-515. https://doi.org/10.1111/ajad.12465.

30. Manzardo AM, Henkhaus RS, Butler MG. Global DNA promoter methylation in frontal cortex of alcoholics and controls. Gene 2012; 498(1): 5-12. https://doi.org/10.1016/j.gene.2012.01.096.

31. Mello MLS, Vidal BC. The Feulgen reaction: A brief review and new perspectives. Acta Histochem 2017; 119(6): 603-609. https://doi.org/10.1016/j.acthis.2017.07.002.

32. Felisbino MB, Gatti MS, Mello ML. Changes in chromatin structure in NIH 3T3 cells induced by valproic acid and trichostatin A. J Cell Biochem 2014; 115(11): 1937-1947. https://doi.org/10.1002/jcb.24865.

33. Felisbino MB, Tamashiro WM, Mello ML. Chromatin remodeling, cell proliferation and cell death in valproic acid-treated HeLa cells. PLOS One 2011; 6(12). https://doi.org/10.1371/journal.pone.0029144.

34. Camby I, Salmon I, Danguy A, Pasteels JL, Kiss R. The use of the digital cell image analysis of Feulgen-stained nuclei to detect apoptosis. Histochem Cell Biol 1995; 104(5): 407-414. https://doi.org/10.1007/BF01458135.

Authors:

Anastasiya S. Babkina - Research Scientist, Laboratory of Cell Pathology in Critical Illness, Federal Research and Clinical Center of Intensive Care Medicine and Rehabilitology, Moscow, Russia. https://orcid.org/00000003-1780-9829.

Maryam B. Khadzhiyeva - PhD, Principal Research Scientist, Laboratory of Clinical Pathophysiology of Critical Illness, Federal Research and Clinical Center of Intensive Care Medicine and Rehabilitology, Moscow, Russia. https://orcid.org/0000-0002-8980-4851.

Irina V. Ostrova - PhD, Principal Research Scientist, Laboratory of Cell Pathology in Critical Illness, Federal Research and Clinical Center of Intensive Care Medicine and Rehabilitology, Moscow, Russia. https://orcid.org/0000-0002-9539-1475.

Ivan A. Ryzhkov - MD, PhD, Senior Research Scientist, Head of Experimental Research Laboratory, Federal Research and Clinical Center of Intensive Care Medicine and Rehabilitology, Moscow, Russia. https://orcid.org/0000-0002-0631-5666.

Arkady M. Golubev - MD, PhD, DSc, Professor, Lead Researcher, Head of the Laboratory of Cell Pathology in Critical Illness, Federal Research and Clinical Center of Intensive Care Medicine and Rehabilitology, Moscow, Russia. https://orcid.org/0000-0002-3165-0378. 